\title{
Author Correction: Mutualist and pathogen traits interact to affect plant community structure in a spatially explicit model
}

\author{
John W. Schroeder (D), Andrew Dobson, Scott A. Mangan, Daniel F. Petticord (1D \& Edward Allen Herre
}

Correction to: Nature Communications https://doi.org/10.1038/s41467-020-16047-5, published online 5 May 2020.

The original version of this Article omitted the following from the Acknowledgements:

Support for this work was provided by Simons Foundation award 429440 (WTW).

This has now been corrected in both the PDF and HTML versions of the Article.

Published online: 26 May 2020

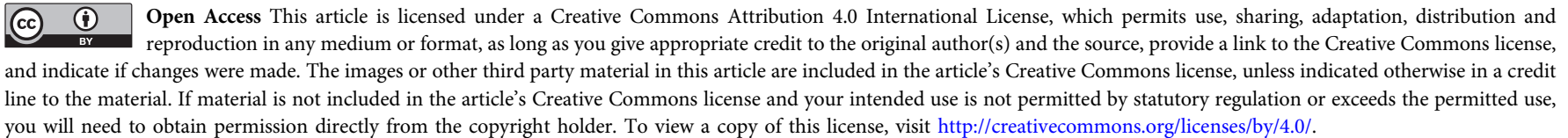

(c) The Author(s) 2020 